\title{
Pengembangan Perangkat Pembelajaran Model $P B L$ Berbantuan Simulasi PhET untuk Meningkatkan Kemampuan Berpikir Tingkat Tinggi
}

\author{
${ }^{1}$ Arman Rizal Gunawan, ${ }^{2}$ Hikmawati, ${ }^{3}$ I Wayan Gunada, ${ }^{4}$ Susilawati \\ ${ }^{1,2,3,4}$ Prodi Pendidikan Fisika, Jurusan Pendidikan MIPA, Fakultas Keguruan dan Ilmu \\ Pendidikan, Universitas Mataram, Jln. Majapahit No.62, Mataram, NTB, 83125.
}

Email Korespondensi: arman.rizal.gun89@gmail.com

\begin{tabular}{|c|c|}
\hline & \\
\hline & \multirow{2}{*}{$\begin{array}{l}\text { This development research aims to produce a product in the form of a physics } \\
\text { learning device with a problem based learning model on Momentum and } \\
\text { Impulse material to improve students' higher-order thinking skills. The type of } \\
\text { research is Research and Development (R\&D) with a } 4 D \text { model consisting of } \\
\text { Define, Design, Develop, and Disseminate. The products developed are } \\
\text { syllabus, online learning implementation plans, student worksheets equipped } \\
\text { with PhET simulation instructions, and higher order thinking ability test } \\
\text { instruments. Product validity was assessed by five validators with Likert scale } \\
\text { analysis. Furthermore, the effectiveness of the device is determined from a } \\
\text { limited trial to get the N-gain value. The results of the study based on the } \\
\text { validator's assessment showed that the overall device developed had an } \\
\text { average value of above } 3.00 \text { in the good category, then the average N-gain test } \\
\text { results obtained a value of } 0.34 \text { in the medium category. Thus, it can be } \\
\text { concluded that the development of problem based learning physics learning } \\
\text { tools on Momentum and Impulse material is valid, and effective for improving } \\
\text { students' higher order thinking skills. }\end{array}$} \\
\hline $\begin{array}{l}\text { Keywords } \\
\text { Learning Device; Problem } \\
\text { Based Learning Model; } \\
\text { PhET simulation; higher- } \\
\text { order thinking skills }\end{array}$ & \\
\hline & \\
\hline $\begin{array}{l}\text { Sejarah Artikel } \\
\text { Diterima: } 31 \text { Agustus } 2021 \\
\text { Direvisi: } 11 \text { Des } 2021 \\
\text { Dipublikasi: } 30 \text { Des } 2021\end{array}$ & \multirow{2}{*}{$\begin{array}{l}\text { Penelitian pengembangan ini bertujuan untuk menghasilkan produk berupa } \\
\text { perangkat pembelajaran fisika model problem based learning pada materi } \\
\text { Momentum dan Impuls untuk meningkatkan kemampuan berpikir tingkat } \\
\text { tinggi peserta didik. Jenis penelitian adalah Research and Development (R\&D) } \\
\text { dengan model 4D terdiri dari Define, Design, Develop, dan Disseminate. } \\
\text { Produk yang dikembangkan berupa silabus, rencana pelaksanaan pembelajaran } \\
\text { daring, lembar kerja peserta didik yang dilengkapi dengan petunjuk simulasi } \\
\text { PhET, dan instrumen tes kemampuan berpikir tingkat tinggi. Validitas produk } \\
\text { dinilai oleh lima validator dengan analisis skala likert. Selanjutnya keefektifan } \\
\text { perangkat ditentukan dari uji coba terbatas untuk mendapatkan nilai N-gain. } \\
\text { Hasil penelitian berdasarkan penilaian validator menunjukkan keseluruhan } \\
\text { perangkat yang dikembangkan memiliki nilai rata-rata diatas } 3.00 \text { dengan } \\
\text { kategori baik, lalu hasil rata-rata uji N-gain didapatkan nilai } 0.34 \text { dengan } \\
\text { kategori sedang. Dengan demikian dapat disimpulkan bahwa pengembangan } \\
\text { perangkat pembelajaran fisika model problem based learning pada materi } \\
\text { Momentum dan Impuls valid, dan efektif untuk meningkatkan kemampuan } \\
\text { berpikir tingkat tinggi peserta didik. }\end{array}$} \\
\hline $\begin{array}{l}\text { Kata kunci } \\
\text { Perangkat Pemb } \\
\text { Model Proble } \\
\text { Learning; Simul } \\
\text { Kemampuan Ber } \\
\text { Tingkat Tinggi }\end{array}$ & \\
\hline \multicolumn{2}{|c|}{$\begin{array}{l}\text { Sitasi: Gunawan, A.R., Hikmawati, H., Gunada, I.W., \& Susilawati, S. (2021), Pengembangan Perangkat } \\
\text { Pembelajaran Model PBL Berbantuan Simulasi PhET untuk Meningkatkan Kemampuan Berpikir Tingkat } \\
\text { Tinggi, Kappa Journal. 5(1), 166-173. }\end{array}$} \\
\hline
\end{tabular}

PENDAHULUAN

Pendidikan adalah sebuah proses yang melibatkan banyak sumber daya, baik itu sumber daya manusia, sumber daya dana maupun sumber daya sarana dan prasarana. Menurut Gunawan (2017), proses berkaitan tentang bagaimana peserta didik menemukan 
konsep yang dipelajari sedangkan produk berkaitan tentang hasil dari proses tersebut seperti prinsip, hukum, konsep, dan persamaan. oleh guru (teacher centered), melainkan didominasi oleh peserta didik (student centered). Sehingga prestasi peserta didik akan menjadi asli atau tidak artifisial belaka. Selain itu, guru dituntut memiliki kemampuan dalam menyusun strategi dan metode mengajar agar proses pembelajaran berjalan optimal. Menurut Trianto (2014) pembelajaran adalah usaha sadar dari seorang guru untuk membelajarkan siswanya (mengerahkan interaksi siswa dengan sumber belajar lainnya) dalam rangka mencapai tujuan yang diharapkan.

Menurut Sudjana (2009), belajar pada hakikatnya adalah proses interaksi terhadap semua situasi yang ada di sekitar individu. Belajar dapat dipandang sebagai proses yang diarahkan kepada tujuan dan proses berbuat melalui berbagai pengalaman. Belajar juga merupakan proses melihat, mengamati, dan memahami sesuatu. Menurut Rusman (2014) proses pembelajaran merupakan suatu proses yang mengandung serangkaian perbuatan guru dan peserta didik atas hubungan timbal balik yang berlangsung dalam situasi edukatif untuk mencapai tujuan tertentu, di mana dalam proses tersebut terkandung multiperan dari guru. Peranan guru meliputi banyak hal, yaitu guru dapat berperan sebagai pengajar, pemimpin kelas, pembimbing, pengatur lingkungan belajar, perencana pembelajaran, supervisor, motivator, dan sebagai evaluator. Pada kenyataannya, Masalah utama dalam pembelajaran fisika yang masih banyak ditemui adalah tentang rendahnya kemampuan berpikir serta semangat belajar siswa. Rusman (2014) mengemukakan, salah satu kecenderungan yang sering dilakukan adalah melupakan hakikat pembelajaran yang sesungguhnya di mana seharusnya pembelajaran lebih berpusat pada siswa, dan bukan pada guru. Oleh karena itu, diperlukan suatu model pembelajaran yang mampu memunculkan keterlibatan.

Salah satu model pembelajaran yang relevan dalam mengatasi pembelajaran fisika tersebut adalah model pembelajaran berbasis masalah (problem based learning /PBL). Prinsipnya dalam model pembelajaran PBL, peserta didik sendirilah yang secara aktif mencari jawaban atas masalah-masalah yang diberikan guru. Dalam hal ini guru lebih banyak sebagai mediator dan fasilitator untuk membantu peserta didik dalam mengkonstruksi pengetahuan mereka secara efektif. Pembelajaran berbasis masalah merupakan pembelajaran yang menyajikan kepada peserta didik situasi masalah yang nyata, yang bersifat terbuka (illstructured). Menurut Arends (2007), beberapa ahli mengatakan Problem Based Learning (PBL) adalah suatu pendekatan pembelajaran yang menggunakan masalah dunia nyata sebagai konteks bagi siswa untuk belajar tentang keterampilan memecahkan masalah. Suharta (2013) menyatakan bahwa penggunaan model problem based learning selama kegiatan pembelajaran membuat siswa lebih berpikir daripada menghafal, memahami pelajaran yang lebih baik melalui diskusi dan bisa menerima model pembelajaran, juga dapat meningkatkan hasil belajar siswa pada kimia, mendorong demokrasi dalam efektivitas belajar dan dapat mengembangkan kreativitas.( et al., 2020)

Media sebagai salah satu perangkat pembelajaran yang dapat digunakan untuk membantu dalam proses pembelajaran. Menurut Hofstteter (dalam Rusman, 2013:296), multimedia adalah pemanfaatan komputer untuk membuat video dan animasi dengan menggabungkan link dan tool untuk melakukan navigasi, berinteraksi, berkreasi, dan berkomunikasi. Simulasi virtual yang digunakan berupa simulasi yang sudah ada yakni program adobe flash player untuk submateri momentum dan impuls dan program Physics Education Technology (PhET) yang telah dipatenkan oleh Universitas Colorado untuk submateri hukum kekekalan momentum dan tumbukan. PhET (Physics Education Technology) merupakan media simulasi yang menarik untuk kepentingan pengajaran di kelas atau belajar individu (Prihatiningtyas et al., 2013) Dengan demikian, dapat disimpulkan bahwa perlu untuk dapat mengembangkan prangkat pembelajaran model PBL dengan berbantuan simulasi PhET untuk meningkatkan kemampuan berpikir tingkat tinggi peserta didik. 


\section{METODE}

Metode penelitian dan pengembangan adalah metode penelitian yang digunakan untuk menghasilkan produk tertentu, dan menguji keefektifan produk tersebut (Sugiyono, 2012: 407). Penelitian pengembangan ini menggunakan jenis peneltian Reasearch and Development (R\&D) dengan 4D Models atau 4 tahapan utama menurut Trianto (2014), yaitu pendefinisian (Define), perancangan (Design), pengembangan (Develop); dan diseminasi (Disseminate) dengan subjek penelitian yaitu peserta didik SMAN 1 Praya Tengah Kelas X MIPA 3 tahun ajaran 2020/2021 yang terdiri dari 16 orang. Teknik pengumpulan data menggunakan lembar validasi dengan skala likert 1-4 yang dinilai oleh lima validator, dengan validator ahli yang terdiri dari tiga dosen dan validator praktisi terdiri dari dua guru. Selanjutnya, dilakukan ujicoba perangkat dalam pembelajaran kepada peserta didik serta dilakukan pre-test dan pos-test untuk mendapatkan nilai $\mathrm{N}$-gain demi menentukan keefektifan perangkat.

Analisis validitas perangkat pembelajaran dam instrumen berbasis model pembelajaran problem based learning berbantuan simulasi PhET untuk meningkatkan kemampuan berpikir tingkat tinggi dicari dengan menggunakan persamaan.

$$
\text { Nilai }=\frac{\text { skor yang diperoleh }}{N \text { skor maksimum }} \times 100 \%
$$

Tabel 1. Kriteria Validitas Perangkat Pembelajaran

\begin{tabular}{cc}
\hline Skor & Kriteria \\
\hline $85,01-100,00 \%$ & Sangat valid \\
\hline $70,01-85,00 \%$ & Cukup Valid \\
\hline $50,01-70,00 \%$ & Kurang valid \\
\hline $01,00-50,00 \%$ & Tidak valid
\end{tabular}

Sumber: Akbar (dalam Fatmawati, 2013).

Analisi keefektifan perangkat pembelajaran didasarkan pada pencapaian siswa dalam menyelesaikan instrument tes kemampuan berpikir tingkat tinggi. Nilai maksimal pada tes hasil belajar adalah 100 dengan kriteria ketuntasan minimal (KKM) yang ditetapkan pada mata pelajaran fisika yaitu 75. Peningkatan kemampuan berpikir tingkat tinggi dapat ditentukan dengan menggunakan Standar Gain dengan persamaan berikut:

$$
\text { Std }<\mathrm{g}>=\frac{\overline{\mathrm{X}}_{\text {sesudah }}-\overline{\mathrm{X}}_{\text {sebelum }}}{\overline{\mathrm{X}}_{\text {maks }}-\overline{\mathrm{X}}_{\text {sebelum }}}
$$

Berdasarkan hasil yang diperoleh dengan menggunakan standar gain, dikelompokkan kategori kemampuan berpikir tingkat tinggi peserta didik sebaga berikut:

Tabel 2. Interprestasi $N$-Gain

\begin{tabular}{cc}
\hline $\boldsymbol{N}$-Gain score $(\mathbf{g})$ & Interprestasi \\
\hline $0,70<\mathrm{g}<1,00$ & Tinggi \\
\hline $0,30<\mathrm{g}<0,70$ & Sedang \\
\hline $0,0<\mathrm{g}<0,30$ & Rendah \\
\hline & (Nuryanto, 2018)
\end{tabular}

\section{HASIL DAN PEMBAHASAN}

Pendefinisian adalah tahapan awal dalam penelitian yang bertujuan menganalisis perangkat pembelajaran untuk menentukan tujuan pembelajaran. Tahap pendefinisian meliputi analisis awal, analisis peserta didik, analisis konsep. Melalui tahap ini diketahui gambaran umum permasalahan proses pembelajaran fisika, sehingga dapat ditentukan tujuan pembelajaran.

Analisis awal bertujuan untuk menetapkan masalah dasar yang dihadapi dalam pembelajaran fisika yang dilakukan di SMAN 1 Praya Tengah meliputi kurikulum dan 
permasalahan lapangan sehingga dibutuhkan pengembangan perangkat pembelajaran. Analisis awal dilakukan dengan mewawancarai salah satu guru kelas X MIPA. Berdasarkan wawancara tersebut didapatkan informasi bahwa kurikulum yang digunakan SMAN 1 Praya Tengah yakni kurikulum terbaru, Kurikulum 2013. Adapun metode yang sering digunakan oleh guru dalam mengajar Fisika yakni metode ceramah dan diskusi. Sehingga siswa kurang aktif dalam proses pembelajaran (teacher center), yang di mana diharapkan siswalah yang lebih aktif dalam proses pembelajaran agar siswa lebih cepat memahami materi yang diajarkan ataupun permasalah dalam materi pembelajaran (student center).

Analisis konsep dilakukan dengan memilih dan mengidentifikasi konsep konsep utama yang digunakan dalam proses pembelajaran. Konsep-konsep tersebut disusun secara sistematis dan rinci sesuai dengan relevansinya.

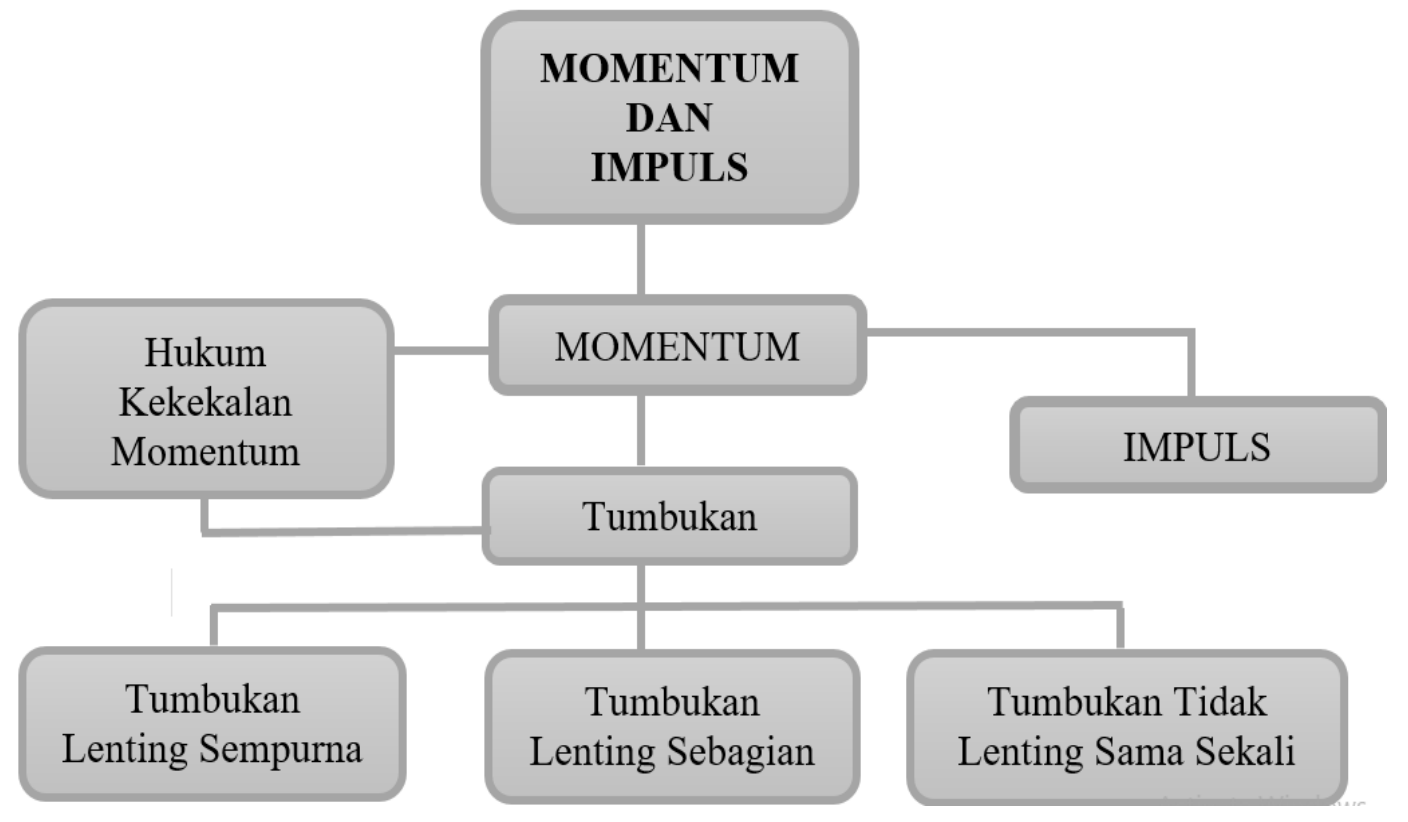

Gambar 1. Peta Konsep Materi Momentum dan Impuls

Tahap perencanaan (design) merupakan tahap merancang draft awal perangkat pembelajaran yang akan digunakan dalam Momentum dan Impuls. Perangkat pembelajaran berbasis model Problem Based Learning dan instrument pengumpulan data yang kemudian divalidasi oleh validator ahli dan validator praktisi.

Tahap pengembangan (develop) merupakan tahap untuk menghasilkan produk pengembangan yang dilakukan melalui dua langkah, yaitu uji validasi produk oleh validator dan uji coba secara terbatas. Uji coba validator bertujuan mevaliditas perangkat yang dikembangkan. Perangkat divalidasi oleh 5 validator yang terdiri dari validator ahli dan validator praktisi. Adapun validator ahli terdiri dari 3 Dosen Universitas Mataram, sedangkan validator praktisi terdiri dari 2 guru yang mengampu mata pelajaran Fisika di SMAN 1 Praya Tengah.

Multimedia merupakan sistem yang mendukung komunikasi guru dengan siswa selama proses pembelajaran melalui teks, audio, gambar, animasi, video, dan grafis (Gunawan et al, 2015:10). Penelitian sebelumnya oleh Hikmawati et al. (2018) yang mengatakan bahwa dengan penerapan media tiga dimensi pada proses pembelajaran memberikan pengalaman langsung pada peserta didik sehingga materi yang disampaikan lebih menarik dan terdapat berbagai hal ilmu pengetahuan yang dapat diambil berhubungan dengan media pembelajaran.

Simulasi virtual yang digunakan berupa simulasi yang sudah ada yakni program adobe flash player untuk submateri momentum dan impuls dan program Physics Education 
Technology (PhET) yang telah dipatenkan oleh Universitas Colorado untuk submateri hukum kekekalan momentum dan tumbukan. PhET (Physics Education Technology) merupakan media simulasi yang menarik untuk kepentingan pengajaran di kelas atau belajar individu (Prihatiningtyas et al., 2013) dan seperti halnya media pembelajaran secara umum yang dapat dipergunakan secara periodik untuk mempermudah proses pembelajaran (Warsita, 2013). Kegunaan PhET seperti halnya media pembelajaran lainnya yang berguna untuk alat bantu mentransformasi pesan (Arham \& Dwiningsih, 2016) Simulasi PhET dan aplikasi lab maya lainnya dapat menggantikan praktikum untuk topik dengan set alat terbatas, berbahaya, dan sulit dilakukan di sekolah (Manikowati \& Iskandar, 2018). Multimedia interaktif dalam pembelajaran fisika dapat membantu peserta didik untuk memahami konsep-konsep yang abstrak karena tidak hanya disajikan dalam bentuk text tetapi dapat disajikan dalam bentuk lain sehingga peserta didikmengalami langsung bagaimana sebenarnya suatu konsep terjadi dalam fenomena nyata, khususnya konsep fisika. Menurut taksonomi Bloom yang telah direvisi proses kognitif terbagi menjadi kemampuan berpikir tingkat rendah (Lower Order Thinking) dan kemampuan berpikir tingkat tinggi (Higher Order Thinking). Kemampuan yang termasuk LOT adalah kemampuan mengingat (understand remember), memahami, dan menerapkan (apply), sedangkan HOT meliputi kemampuan menganalisis (analyze), mengevaluasi (evaluate), dan menciptakan (create) (Anderson dan Krathwohl, 2001: 30).

Uji coba terbatas bertujuan untuk melihat Keefektifan prangkat dalam hal meningkatkan kemampuan berpikir tingkat tinggi peserta didik. Mengetahui keefektifan perangkat pembelajaran dilakukan pengambilam data yang dilakukan di salah satu sekolah Negeri di Lombok Tengah yakni SMAN 1 Praya Tengah, sehingga diperoleh yaitu data peningkatan kemampuan berpikir tingkat tinggi melalui pretest dan postest dengan uji $\mathrm{N}$-gain setelah mengikuti pembelajaran.

Berikut rata-rata penilaian perangkat oleh validator ahli yang terdiri dari 3 dosen

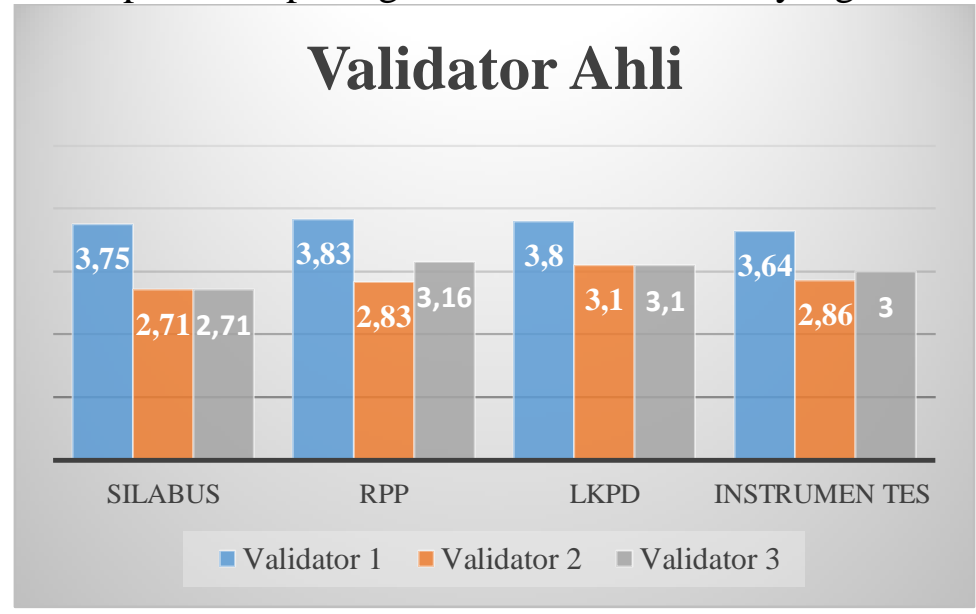

Gambar 2. Hasil Validasi oleh Validator Ahli

Berikut rata-rata penilaian perangkat oleh validator praktisi yang terdiri dari 2 guru mata pelajaran 


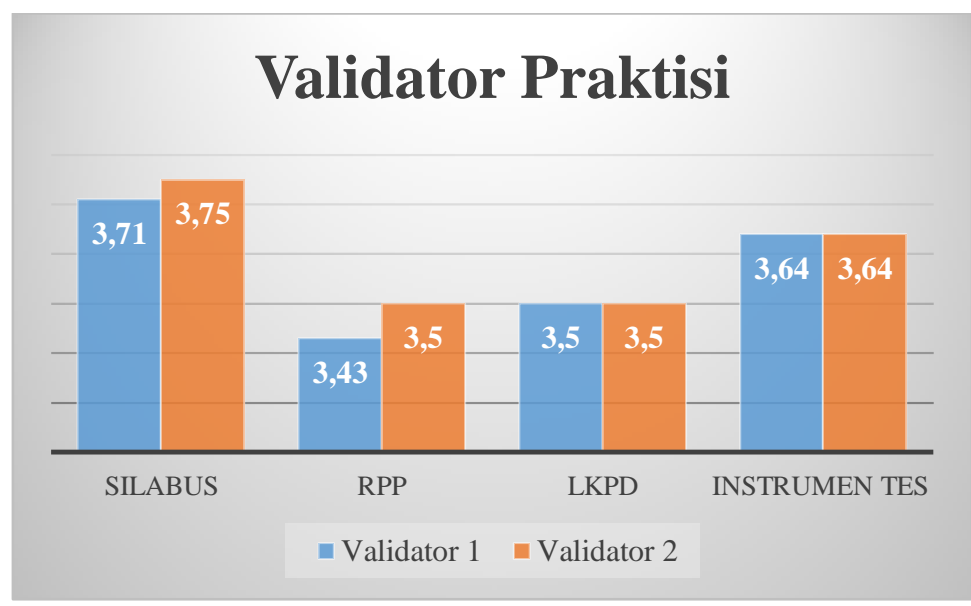

Gambar 3. Hasil Validasi oleh Validator Praktisi

Dari tabel 4 dan 5 serta grafik 1 dan 2 nilai rata-rata perangkat dari validator ahli menunjukkan nilai di atas 3,00 dengan kategori baik, sedangkan dari validator praktisi menunjukkan nilai diatas 3,50 dengan keseluruhan berkategori sangat baik.

Berdasarkan hasil pretest dan postest kelas X MIPA 3 sebanyak 16 orang secara keseluruhan nilai rata-rata $\mathrm{N}$-gain sebesar 0,32 dengan kategori sedang. Hal ini menandakan terjadi peningkatan hasil belajar peserta didik walaupun tidak terlalu signifikan. Pada kelas $\mathrm{X}$ MIPA 3 diperoleh 0 orang dalam kategori tinggi, 8 orang masuk dalam kategori sedang, dan 8 orang dalam kategori rendah.

Tabel 3. Analisis Rata-rata Instrumen Tes melalui Uji N-gain pada Kelas X MIPA 3

\begin{tabular}{rcc}
\hline$\overline{\boldsymbol{X}}_{\text {sebelum }}$ & $\overline{\boldsymbol{X}}_{\text {sesudah }}$ & $\boldsymbol{N}$-gain \\
\hline 37,25 & 58,69 & 0,34 \\
\hline
\end{tabular}

Analisis Kategori Uji N-gain pada kelas X MIPA 3 bisa dilihat melalui table berikut:

Tabel 4. Analisis Kategori Uji N-gain pada Kelas X MIPA 3

\begin{tabular}{ccc}
\hline $\boldsymbol{N}$-Gain score $(\boldsymbol{g})$ & Interprestasi & Jumlah Peserta Didik \\
\hline $\mathbf{0 , 7 0}<\mathbf{g}<\mathbf{1 , 0 0}$ & Tinggi & 0 \\
\hline $\mathbf{0 , 3 0}<\mathbf{g}<\mathbf{0 , 7 0}$ & Sedang & 8 \\
\hline $\mathbf{0 , 0}<\mathbf{g}<\mathbf{0 , 3 0}$ & Rendah & 8
\end{tabular}

Dari table 5 dan 6 kita bisa melihat keefektifan dari perangkat pembelajaran yang diberikan kepada peserta didik. didapatkan hasil bahwa nilai rata-rata N-gain 16 peserta didik sebesar 0.32 dengan kategori sedang dengan rincian 0 peserta didik masuk dalam kategori tinggi, 8 peserta didik masuk dalam kategori sedang, dan 8 peserta didik masuk dalam kategori rendah, sehingga dari hasil $\mathrm{N}$-gain 0,32 menunjukkan bahwa perangkat pembelajaran efektif digunakan dalam proses pembelajaran untuk meningkatkan kemampuan berpikir tingkat tinggi peserta didik.

Hasil penelitian tersebut sesuai dengan beberapa penelitian lain seperti: 1) Penerapan Problem Based Learning melalui simulasi phet untuk meningkatkan pemahaman konsep siswa pada materi energi mekanik di SMA (Yanti et. al., 2019). 2) Efektivitas model PBL berbantuan simulasi PhET pada pokok bahasan elastisitas dan hukum Hooke untuk meningkatkan kemampuan multirepresentasi siswa SMA (Hidyanti, 2018). 3) Mengidentifikasi kecakapan High Order Thinking Skills (HOTS) siswa SMA Negeri 3 Yogyakarta melalui penerapan model pembelajaran Problem Based Learning (PBL) (Efvinggo, 2021). 4) Penggunaan simulasi virtual pada pembelajaran fisika untuk meningkatkan Higher Order Thinking Skill (HOTS) siswa : meta-analisis (Miftahul et. al., 2020). Faktor yang mempengaruhi kemampuan berpikir tingkat tinggi peserta didik terletak di awal pembelajaran. Masalah yang dimunculkan dari simulasi PhET, animasi lebih mempermudah siswa dalam memahami sesuatu dari pada yang lain. Hal ini sesuai dengan 
pernyataan Sukiyasa (2013) media animasi lebih tinggi dari hasil belajar dan motivasi belajar siswa yang diajarkan dengan media powerpoint.

\section{KESIMPULAN}

Perangkat pembelajaran model Problem Based Learning berbantuan simulasi PhET pada materi Momentum dan Impuls layak untuk meningkatkan kemampuan berpikir tingkat tinggi sehingga dapat digunakan dalam pembelajaran.

\section{SARAN}

Dalam penelitian ini, pembelajaran hanya menggunakan bahan ajar dan simulasi $\mathrm{PhET}$ untuk materi Momentum dan Impuls, oleh karena itu diharapkan ada penelitian serupa yang menggunakan materi ajar lainnya serta perlu dilakukannya pengenalan terlebih dahulu terkait simulasi PhET kepada peserta didik sebelum masuk pembelajaran.

\section{DAFTAR PUSTAKA}

Akbar, S. 2013. Instrumen Perangkat Pembelajaran. Bandung: Remaja Rosdakarya Offset

Anderson, L.W., dan Krathwohl, D.R. 2001. A Taxonomy for Learning, Teaching, and Assesing: A revision of Bloom's Taxonomy of Education Objectives. New York: Addison Wesley Longman, Inc.

Arends, Richard I. 2007. Learning to Teach: Belajar untuk Mengajar (Edisi 7 Jilid 1). Yogyakarta: Pustaka Pelajar.

Arham, U. U., \& Dwiningsih, K. (2016). Keefektifan Multimedia Interaktif Berbasis Blended Learning untuk Meningkatkan Hasil Belajar Siswa. Kwangsan:Jurnal Teknologi Pendidikan, 4(2), 111.

Gunawan. 2017. Keterampilan Berpikir dalam Pembelajaran Sains. Mataram: Arga Puji Press.

Gunawan, G., Harjono, A., \& Sahidu, H. 2015. Pengembangan Model Laboratorium Virtual Berorientasi Pada Kemampuan Pemecahan Masalah Bagi Calon Guru Fisika. Jurnal Materi dan Pembelajaran Fisika 5(2), 41-46.

Gunawan, G., Harjono, A., \& Sutrio, S. 2015. Multimedia Interaktif dalam Pembelajaran Konsep Listrik Bagi Calon Guru. Jurnal Pendidikan Fisika dan Teknologi 1(1), 9-14.

Hikmawati, H., Rokhmat, J., \& Sutrio, S. 2018. Penyuluhan Pembuatan Media Tiga Dimensi dan Penerapannya Melalui Model Siklus Belajar 5E Pada Guru-Guru di MGMP Fisika SeLombok Barat. Jurnal Pendidikan dan pengabdian Masyarakat, 1(1).

Manikowati, Nf., \& Iskandar, D.( 2018). Pengembangan Model Mobile Siswa SMA. Kwangsan: Jurnal Teknologi Pendidikan, (1), 23.

Nuryanto, A. P. 2018. Pengembangan Perangkat Pembelajaran Fisika Berbasis Problem Based Learning Untuk Meningkatkan Prestasi Dan Minat Belajar Peserta Didik SMA. Yogyakarta: Lembaga Penelitian Universitas Negeri Yogyakarta.

Prihatiningtyas, S., Prastowo, T., \& Jatmiko, B. (2013). Imlementasi simulasi phet dan kit sederhana untuk mengajarkan keterampilan psikomotor siswa pada pokok bahasan alat optik. Jurnal Pendidikan IPA Indonesia, 2(1), 18- 22.

Prihatiningtyas, S., Prastowo, T., \& Jatmiko, B. (2013). Imlementasi simulasi phet dan kit sederhana untuk mengajarkan keterampilan psikomotor siswa pada pokok bahasan alat optik. Jurnal Pendidikan IPA Indonesia, 2(1), 18- 22. 
Rusman, Kurniawan, D, dan Riyana, C. 2013. Pembelajaran Berbasis Teknologi Informasi dan Komunikasi. Jakarta: PT Rajagrafindo Persada.

Rusman. 2014. Model-model Pembelajaran (Mengembangkan Profesionalisme Guru). Jakarta: Raja Grafindo Persada.

Sudjana, Nana.2009. Penilaian Hasil Proses Belajar Mengajar. Bandung: PT. Remaja Rosdakarya.

Sugiyono. 2012. Metode Penelitian Kuantitatif Kualitatif dan R\&B. Bandung: Alfabeta

Suharta, Luthan, dan Putri, L. A., 2013, Application of Cooperative Problem-Based Learning Model to Develop Creativity and Foster Democracy, and Improve Student Learning Outcomes in Chemistry in High School, Journal of Education and Practice, Vol 4, No 25, Hal. 55- 60 .

Sukiyasa Kadek dan Sukoco. (2013). Pengaruh Media Animasi Terhadap Hasil Belajar dan Motivasi Belajar Siswa Materi Sistem Kelistrikan Otomotif. Jurnal Pendidikan Vokasi, 3(1).

Trianto, 2014. Mendesain Model Pembelajaran Inovatif, Progresif, dan Kontekstual. Jakarta: Prenadamedia Group.

Warsita, B. 2013. Perkembangan Definisi dan Kawasan Teknologi Pembelajaran Serta Perannya dalam Pemecahan Masalah Pembelajaran. Kwangsan: Jurnal Teknologi Pendidikan, 1(2), 72.

Yunita, N., Zahara, L., \& Syahidi, K. (2020). Pengaruh Model Problem Based Learning (PBL) Melalui Lesson Study Terhadap Kemampuan Berpikir Kritis Siswa. Kappa Journal, 4(2), 233239. https://doi.org/10.29408/kpj.v4i2.2756 